\title{
Confronting the Prevalence of Limb Amputation from Peripheral Artery Disease in Nigeria
}

Sir,

This letter aims at highlighting our local challenges in reducing the high prevalence of limb amputation due to peripheral artery disease (PAD) in Nigeria.

Recent data from peripheral vascular ultrasound registry at our institution revealed that up to $29.5 \%$ of patients have evidence of significant luminal stenosis. ${ }^{[1]}$ In Southern Nigeria, the amputation rate in PAD is as high as $72.2 \%{ }^{[2]}$ at the same time, amputation rates in the United States recorded a decrease from $7.26 \%$ to $5.79 \%{ }^{[3]}$

Despite the high burden of PAD and limb amputations, there are limited facilities and expertise for percutaneous transluminal angioplasty (PTA) in Nigeria. Even where the services are available, there is lack of awareness, high cost, and limited supply of devices and consumables, limiting the positive impact of these services to the community.

Our preliminary experience of 25 cases of PAD who were treated with PTA at our institution from Northwestern Nigeria revealed that six of them had either type $\mathrm{C}$ or type $\mathrm{D}$ aorto-iliac disease in addition to distal lesions. At 6-month follow-up, nine of them had limb amputation, while one patient died a day after the procedure. Out of those who had amputation, six were diabetic. Figures 1-3 represent an example of a patient who had complete resolution of symptoms and blood flow restoration after balloon angioplasty.

Amputation rate is high in our community due to numerous limitations such as late presentation,

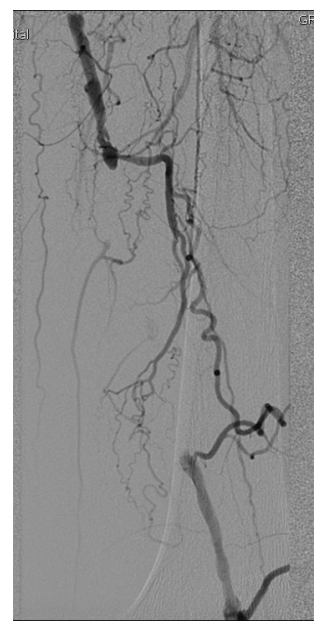

Figure 1: Digital subtraction angiogram of the superficial femoral artery showing severe occlusive disease at its origin. There are numerous collaterals opacifying the distal stump of the superficial femoral artery limited diagnostic facilities (largely relied on Doppler ultrasound), and few functional facilities for endovascular therapy. Currently, there are only four centers serving more than 180 million Nigerians. Even in these few centers, there is serious limitation of ideal devices in addition to the lack of bail-out facilities (stenting, drug-eluding balloons, bypass surgeries, etc.). Furthermore, there are even fewer experts dedicated to the surgical management of peripheral vascular disease. ${ }^{[4]}$ As a result, majority of patients with PAD end up with amputation in Nigeria. We feel that improving the availability of angiographic facilities, trained workforce, and appropriate tools/ consumables will significantly improve the outcomes of endovascular care of PAD in Nigeria.

Therefore, here, we voice out these challenges so that policymakers, clinical societies, organizations, researchers, and industry may develop interest in supporting our humble efforts in improving the quality of care to patients with PAD in Nigeria.

\section{Acknowledgment}

The authors would like to thank the members of the Department of Radiology, Bayero University and Aminu Kano Teaching Hospital, Kano, Nigeria.

Financial support and sponsorship

Nil.

Conflicts of interest

There are no conflicts of interest.

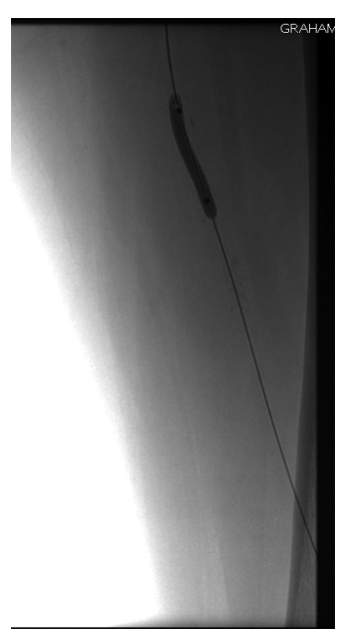

Figure 2: Unsubtracted angiogram of the superficial femoral artery showing serial balloon dilatation of the superficial femoral artery 


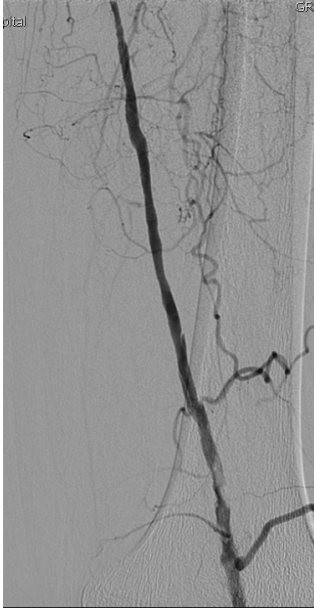

Figure 3: Digital subtraction postangioplasty angiogram showing restoration of blood flow through the superficial femoral artery

\section{Anas Ismail, Abdulkadir Musa Tabari, Kabiru Isyaku, Nafiu Ahmed ${ }^{1}$}

Department of Radiology, College of Health Sciences, Bayero University, ${ }^{\prime}$ Department of Radiology, Aminu Kano Teaching Hospital, Kano, Nigeria

Address for correspondence: Dr. Anas Ismail,

Department of Radiology, College of Health Sciences, Bayero University, Kano, Nigeria. E-mail: aismail.rad@buk.edu.ng

\section{References}

1. Ismail A, Saleh MK, Tabari AM, Isyaku K. Clinical and
Doppler ultrasound evaluation of peripheral arterial diseases in Kano, North-Western Nigeria. Niger Postgrad Med J 2015;22:217-22.

2. Ndukwu CU, Muoneme CA. Prevalence and pattern of major extremity amputation in a tertiary Hospital in Nnewi, South East Nigeria. Trop J Med Res 2015;18:104-8.

3. Jones WS, Patel MR, Dai D, Subherwal S, Stafford J, Calhoun $\mathrm{S}$, et al. Temporal trends and geographic variation of lower-extremity amputation in patients with peripheral artery disease: Results from U.S. Medicare 2000-2008. J Am Coll Cardiol 2012;60:2230-6.

4. Adeoye PO, Adebola SO, Adesiyun OA, Braimoh KT. Peripheral vascular surgical procedures in Ilorin, Nigeria: Indications and outcome. Afr Health Sci 2011;11:433-7.

This is an open access journal, and articles are distributed under the terms of the Creative Commons Attribution-NonCommercial-ShareAlike 4.0 License, which allows others to remix, tweak, and build upon the work non-commercially, as long as appropriate credit is given and the new creations are licensed under the identical terms.

\begin{tabular}{|l|l|}
\multicolumn{2}{|c|}{ Access this article online } \\
\hline Quick Response Code: & Website: \\
& www.arabjir.com \\
\cline { 2 - 3 } & DOI: \\
\hline
\end{tabular}

How to cite this article: Ismail A, Tabari AM, Isyaku K, Ahmed N. Confronting the prevalence of limb amputation from peripheral artery disease in Nigeria. Arab J Intervent Radiol 2018;2:95-6. 